\title{
Oncogenic epithelial cell-derived exosomes containing Rac1 and PAK2 induce angiogenesis in recipient endothelial cells
}

\author{
Shashi K. Gopal' ${ }^{1}$ David W. Greening ${ }^{1}$, Eric G. Hanssen ${ }^{2}$, Hong-Jian Zhu ${ }^{3}$, Richard \\ J. Simpson ${ }^{1}$, Rommel A. Mathias ${ }^{1}$ \\ ${ }^{1}$ Department of Biochemistry and Genetics, La Trobe Institute for Molecular Science, La Trobe University, Melbourne, Victoria, \\ Australia \\ ${ }^{2}$ Bio21 Institute, The University of Melbourne, Melbourne, Victoria, Australia \\ ${ }^{3}$ Department of Surgery, The University of Melbourne, Melbourne, Victoria, Australia \\ Correspondence to: Rommel A. Mathias, e-mail: r.mathias@latrobe.edu.au
}

Keywords: epithelial-mesenchymal transition, exosome, angiogenesis, tumour microenvironment, extracellular vesicle Received: December 01, 2015

Accepted: February 06, 2016

Published: February 22, 2016

\section{ABSTRACT}

The metastatic cascade describes the escape of primary tumour cells to distant secondary sites. Cells at the leading tumour edge are thought to undergo epithelialmesenchymal transition (EMT), to enhance their motility and invasion for spreading. Whether EMT cells directly promote tumour angiogenesis, and the role of exosomes (30-150 $\mathrm{nm}$ extracellular vesicles) remains largely unknown. We examined the functional effects of exosomes from MDCK cells, MDCK cells stably expressing YBX1 (MDCK ${ }^{\text {YBX1 }}$, intermediate EMT), and Ras-transformed MDCK cells (21D1 cells, complete EMT). 2F-2B cell motility and tube formation (length and branching) was significantly increased following supplementation with MDCK $^{\text {YBX1 }}$ or 21D1 exosomes, but not MDCK exosomes. Next, Matrigel ${ }^{\mathrm{TM}}$ plugs containing exosome-supplemented 2F-2B cells were subcutaneously injected into mice. Systemic perfusion was only observed for plugs supplemented with $\mathrm{MDCK}^{\mathrm{YBX} 1}$ or 21D1 exosomes. Comparative proteomics revealed that 21D1 exosomes contained VEGF-associated proteins, while MDCK ${ }^{\text {YBX1 }}$ exosomes were enriched with activated Rac1 and PAK2. To validate, 2F-2B cells and HUVECs were pre-treated with PAK inhibitors prior to exosome supplementation. PAK inhibition nullified the effects of MDCK $^{\mathrm{YBX} 1}$ exosomes by reducing the tube length and branching to baseline levels. By contrast, the effects of 21D1 exosomes were not significantly decreased. Our results demonstrate for the first time that oncogenic cells undergoing EMT can communicate with endothelial cells via exosomes, and establish exosomal Rac1/PAK2 as angiogenic promoters that may function from early stages of the metastatic cascade.

\section{INTRODUCTION}

Interactions occurring between tumour cells at the invasive front and cells in the tumour microenvironment (TM) promote cancer invasion and metastasis [1-4]. Cells at the leading tumour edge are thought to undergo epithelial-mesenchymal transition (EMT) in response to a variety of growth factors, signalling molecules and transcription factors [5]. EMT results in heightened cell motility and invasiveness through diminished cell-cell and cell-matrix adhesion, reorganisation of the cytoskeleton, and remodelling of the ECM [6]. Importantly, EMT is involved in the process of cancer cell intravasation into blood and/or lymph vessels [6, 7]. However, the contribution of EMT cells to the recruitment of endothelial cells and the formation of blood vessels remains not well understood.

Tumour angiogenesis and vessel formation can be controlled by signals in the TM that permit vascular remodelling via a series of controlled events $[8,9]$. Stimulation and activation of endothelial cells drives their detachment from junctional adhesions, sprouting, and migration and proliferation, forming provisional tubes and functional networks [8]. Secreted molecules have the 
ability to influence endothelial cell behaviour [10]. For example, growth factors (VEGF, PDGF, FGF), signalling molecules (TGF- $\beta$, Notch, Wnt, ANG and TIE), integrins $\left(\alpha_{\mathrm{v}} \beta_{3}\right.$ and $\alpha_{\mathrm{v}} \beta_{5}$ ) and proteases (membrane type 1-MMP and MMP9) are known to regulate endothelial cell functions and neovascularisation [11]. Given that extracellular vesicles $(\mathrm{EV})$ have recently been reported as modulators of the TM $[12,13]$, we speculate that they may also promote angiogenesis.

Cancer cells can communicate with recipient endothelial cells through nano-sized 30-150 nm EVs known as exosomes [14-18]. Exosomes from leukemic and glioblastoma cells have been shown to increase endothelial cell tube formation and neovascularisation in in vivo matrigel plugs $[14,15,18]$. Micro-RNA, miR92a contained in leukaemia-derived exosomes stimulated endothelial cell migration and tube formation[16]. Despite the identification of these molecular effectors beginning to emerge, precisely when tumour angiogenesis is initiated, in the context of the metastatic cascade, remains to be defined. Moreover, the ability of EMT cells to promote tumour angiogenesis has not yet been investigated.

We have previously shown that constitutive expression of H-Ras in MDCK cells (21D1 cells) induces all the phenotypic hallmarks of EMT, and characterized alterations to the secretome, plasma membrane, and exosome protein profiles [19-22]. More recently, we have been interested in defining the earlier events that may give rise to the partial EMT (p-EMT) phenotype. Stable expression of the pleiotropic transcription/splicing factor and RNA-binding protein, nuclease-sensitive element-binding protein 1 (YBX1/YB-1), increased the oncogenicity of MDCK cells $\left(\mathrm{MDCK}^{\mathrm{YBX} 1}\right)$ and increased secretion of soluble-secreted proteins associated with promoting angiogenesis [23]. In the present study, we investigated the downstream functional consequences of treating recipient endothelial cells with exosomes derived from MDCK, MDCK ${ }^{\mathrm{YBX} 1}$, and 21D1 cells. We discovered that as oncogenicity increases $\left(\mathrm{MDCK}^{\mathrm{YBX} 1}\right.$ $<21 \mathrm{D} 1$ cells), so does the potency of the cell-derived exosomes to induce angiogenesis in recipient endothelial cells. Nonetheless, exosomes derived from MDCK ${ }^{\mathrm{YBX} 1}$ cells induced a pronounced angiogenic response, and this suggests that tumour angiogenesis may commence during early stages of the metastatic cascade, such as by p-EMT cells.

\section{RESULTS}

We have previously observed that over-expression of YBX1 in MDCK cells induces p-EMT, and causes elevated release of soluble secreted proteins (TGF- $\beta$, CSF-1, NGF, VGF, ADAM9 and ADAM17) associated with promoting angiogenesis [23]. In this current study, we focussed on the functional contribution exosomes derived from increasingly oncogenic EMT cells (MDCK $<$ MDCK $\left.^{\mathrm{YBX} 1}<21 \mathrm{D} 1\right)$ may have on inducing angiogenesis in recipient endothelial cells.

\section{Isolation and characterisation of extracellular vesicles}

EVs were isolated from MDCK, MDCK ${ }^{\mathrm{YBX} 1}$ and 21D1 cells using established workflows (Supplementary Figure S1) based on OptiPrep ${ }^{\mathrm{TM}}$ density gradient ultracentrifugation [22, 24]. Western blotting analysis showed Fraction 7, corresponding to a density of 1.09 $\mathrm{g} / \mathrm{mL}$, to have the greatest expression of exosome markers (Supplementary Figure S2), and was selected for further characterization. Fraction 7 vesicles from all cell lines showed robust expression of ESCRT machinery proteins Alix and TSG101 (Figure 1a), and scanning electron microscopy revealed spherical architecture with textured surfaces (Figure 1b). Additionally, cryo-electron microscopy and cross sectional analysis displayed densely-staining vesicular contents (Figure 1c), while size distribution indicated a homogenous population of vesicles ranging between 50-140 nm (Figure 1d). Additionally, dynamic light scattering indicated a slightly increasing mean vesicle diameter measuring $84.2 \mathrm{~nm}$ (MDCK), $95.5 \mathrm{~nm}\left(\mathrm{MDCK}^{\mathrm{YBX} 1}\right)$ and $(108.5 \mathrm{~nm})$ (21D1) (Figure 1e). Based on these observed characteristics, Fraction 7 vesicles were classified as exosomes and used in downstream experiments.

\section{Exosomes can be internalized by recipient endothelial cells}

The biological function of exosomes as delivery vehicles is underpinned by their ability to deliver cargo into recipient cells. To establish whether exosomes from all three EMT model cell lines could be internalized by endothelial cells, we monitored uptake in 2F-2B cells using confocal microscopy. Exosomes were labelled with the lipophilic cationic indocarbocyanine dye DiI, and supplemented to $2 \mathrm{~F}$ 2B cells. Following a $2 \mathrm{hr}$ incubation, confocal imaging was performed and demonstrated association of the fluorescent dye with the cells (Figure 2a). Furthermore, Z-stack analysis verified that the fluorescence signal does indeed emanate from within the 2F-2B cells, and not only from extracellular membrane interaction (Figure 2b).

\section{Exosomes from oncogenic MDCK ${ }^{\mathrm{YBX} 1}$ and 21D1 cells promote $2 \mathrm{~F}-2 \mathrm{~B}$ cell angiogenesis}

We next investigated the functionality of exosomes from the EMT model cell lines to enhance angiogenic behaviour of endothelial cells in vitro and in vivo. Firstly, following pre-treatment with exosomes, recipient $2 \mathrm{~F}$ 2B cell motility was assessed using transwell assay. Motility of 2F-2B cells treated with MDCK exosomes showed no change, compared to the vehicle control (no exosome supplementation), while $2 \mathrm{~F}-2 \mathrm{~B}$ cell migration was significantly enhanced by $\mathrm{MDCK}^{\mathrm{YBX} 1}$ or $21 \mathrm{D} 1$ cell exosomes (Figure 3a). Next, recipient 2F-2B tube formation 


\section{Exos:}

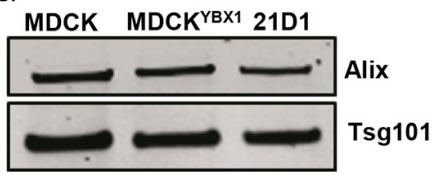

b

MDCK

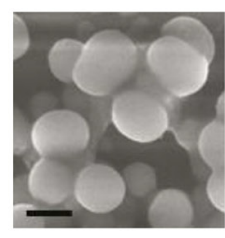

c

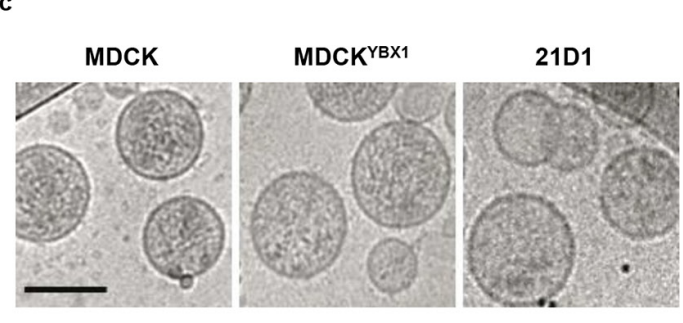

21D1
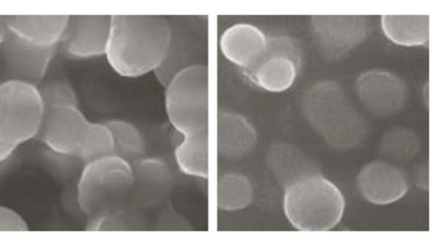

d

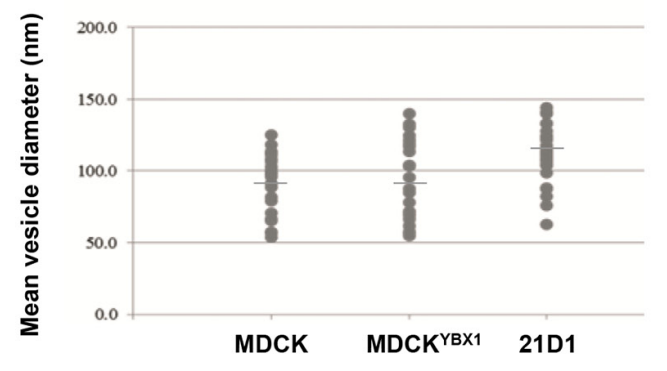

e

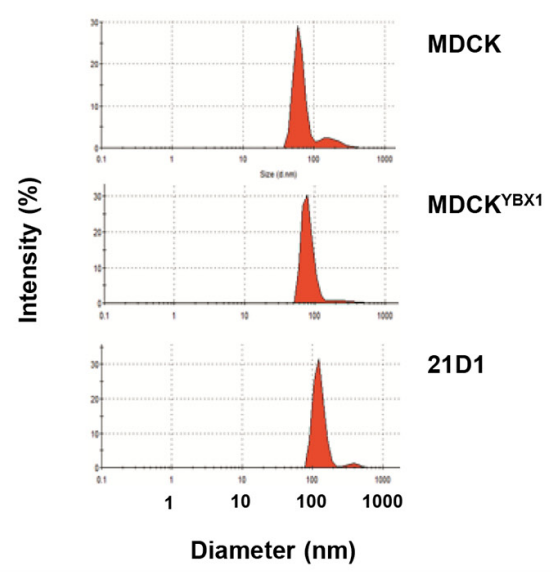

Figure 1: Isolation and characterisation of exosomes from EMT cell lines. a. Exosomes were isolated, purified and examined for expression of exosome markers Alix and TSG101 by western immuno-blotting. b. Vesicle morphology assessed by scanning electron microscopy. Representative image from $\mathrm{n}=3$ and 5 independent fields of view. Scale bar $=100 \mathrm{~nm}$. c. Analysis of exosomes by cryo-electron microscopy. Representative image from $\mathrm{n}=3$ and 5 independent fields of view. Scale bar $=100 \mathrm{~nm}$ d. Distribution of exosome diameter by cryo-electron microscopy (average from $n=3,5$ independent fields of view). e. Exosome diameter assessed by dynamic light scattering $(n=3)$. 
was assessed, and cells stimulated with $\mathrm{MDCK}^{\mathrm{YBX} 1}$ and 21D1 cell exosomes exhibited increased vessel length and number of vessels (Figure 3b). Finally, we utilized matrigel plugs to examine in vivo angiogenic behaviour of recipient 2F-2B cells. Exosome-treated 2F-2B cells embedded in matrigel were subcutaneously injected into NOD/SCID mice, and after 21 days, tail vein injections of FITCdextran were administered. Matrigel plugs were excised and imaged (Supplementary Figure S3). Furthermore, sectioning of plugs and fluorescence imaging revealed the absence of FITC-dextran in MDCK exosome-treated cell plugs, indicating no systemic perfusion (Figure 3c-3d). By contrast, plugs conditioned with $\mathrm{MDCK}^{\mathrm{YBX} 1}$ or $21 \mathrm{D} 1$ cell exosomes stained strongly for FITC-dextran (Figure $3 c-3 d$ ), indicating presence of vessels perfused by the circulation. Together, this data demonstrates that exosomes

a

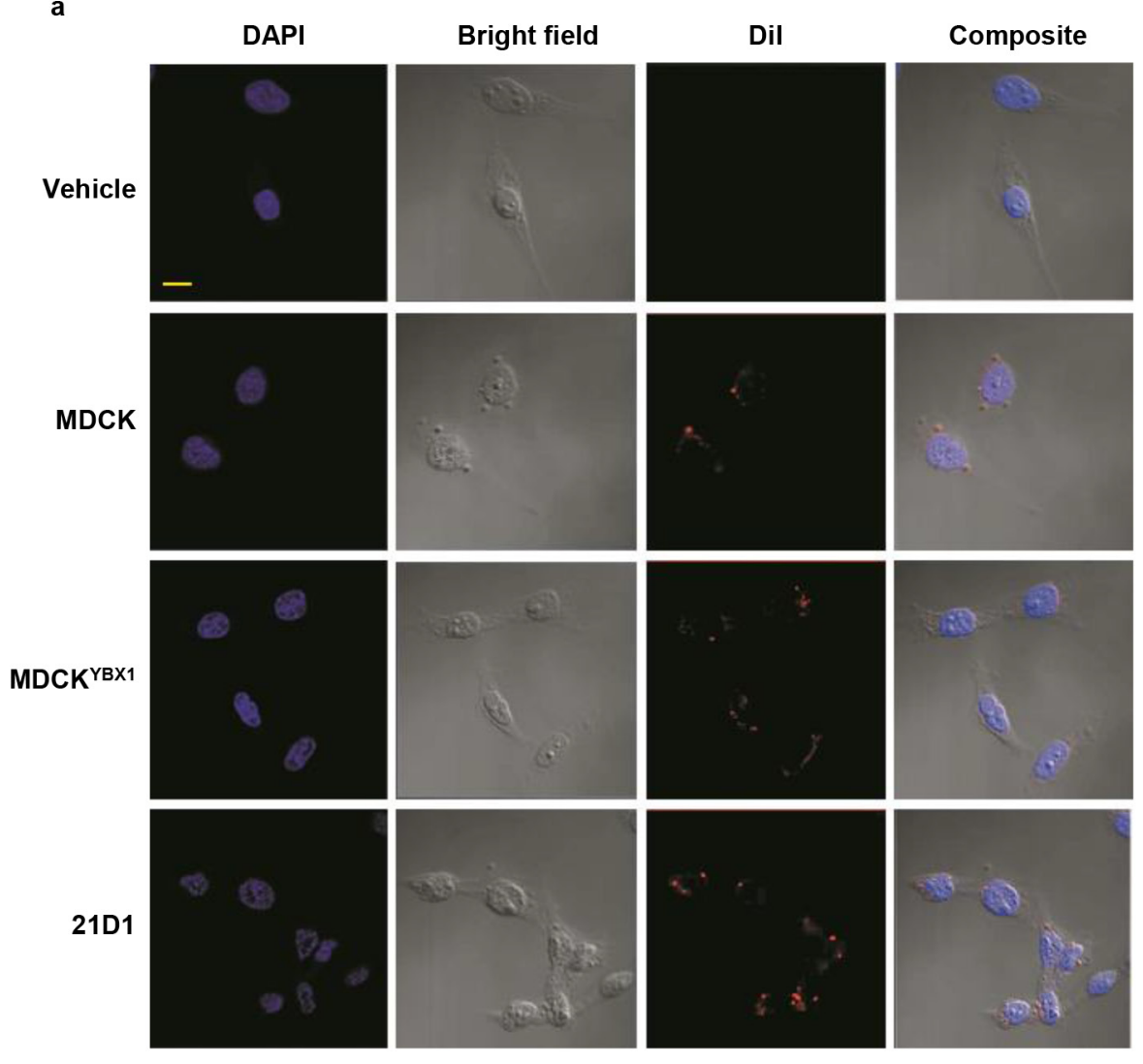

b

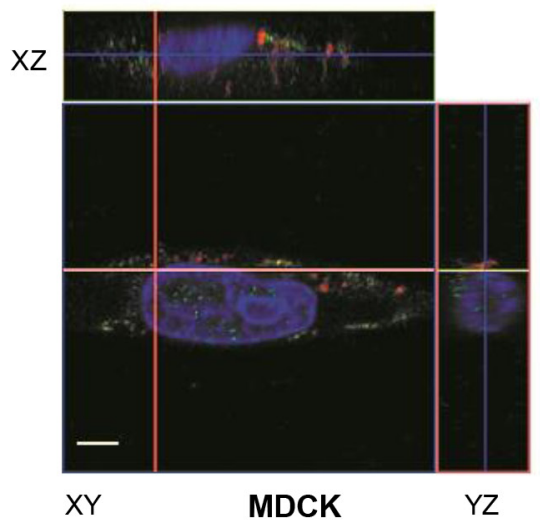

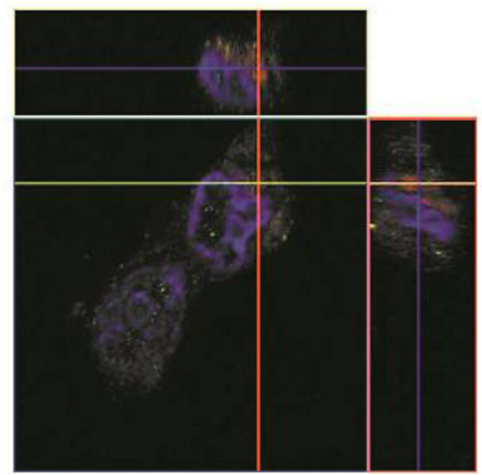

MDCK $^{\mathrm{YBX} 1}$

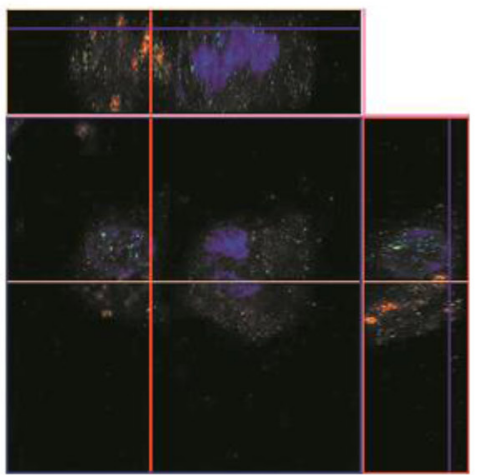

21D1

Figure 2: EMT cell exosomes are internalised by recipient endothelial cells. a. $10 \mu \mathrm{g}$ of exosomes were isolated and labelled with $1 \mu \mathrm{M}$ DiI (red). Exosomes, or vehicle (DMEM) were supplemented to 2F-2B cells for $2 \mathrm{~h}$, and stained with DAPI (blue) prior to confocal and bright-field microscopy. Scale bar $=10 \mu \mathrm{m}$ (representative images from $\mathrm{n}=3$ ). b. Following supplementation of labelled exosomes with DiI (red) for 2 h, 2F-2B cells were fixed, permeabilized and stained with DAPI (blue), and anti-actin antibodies (green). Z-stack images of cells were generated by confocal microscopy. Scale bar $=5 \mu \mathrm{m}(n=3)$. 
derived from oncogenic epithelial cells undergoing EMT, but not normal epithelial cells, can promote angiogenesis in recipient endothelial cells.

\section{Proteomics-based identification of exosomal proteins}

To identify protein constituents in the exosomes involved in conferring pro-angiogenic properties,

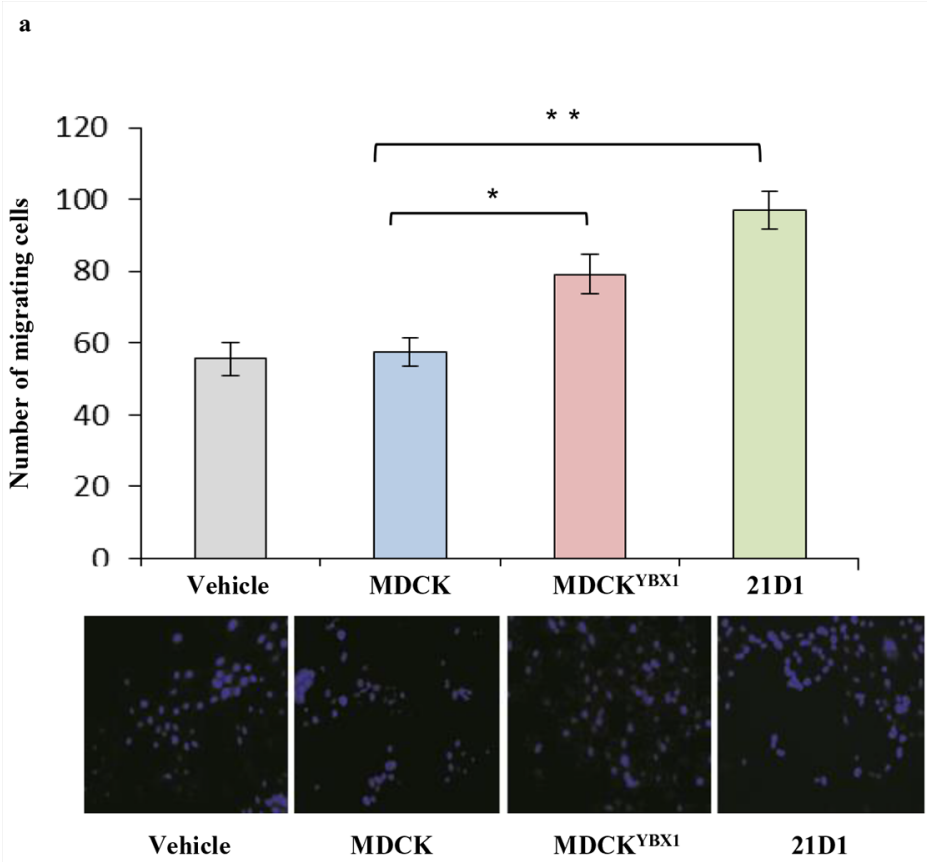

b

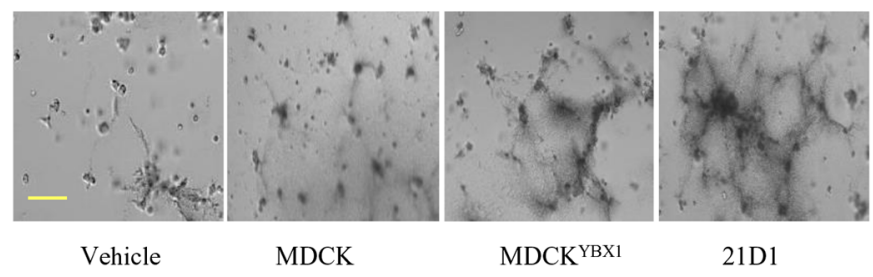

exosomes from all three cell lines were subjected to mass spectrometry analysis. As expected, the exosome protein composition showed some similarities (356 proteins), as well as unique protein characteristics (Supplementary Figure S4, and Supplementary Tables S1-S2). Given we have previously compared MDCK and 21D1 exosomes [22], we focussed on examining MDCK and MDCK $^{\mathrm{YBX} 1}$ exosome composition. Label-free quantification revealed that 161 proteins were significantly
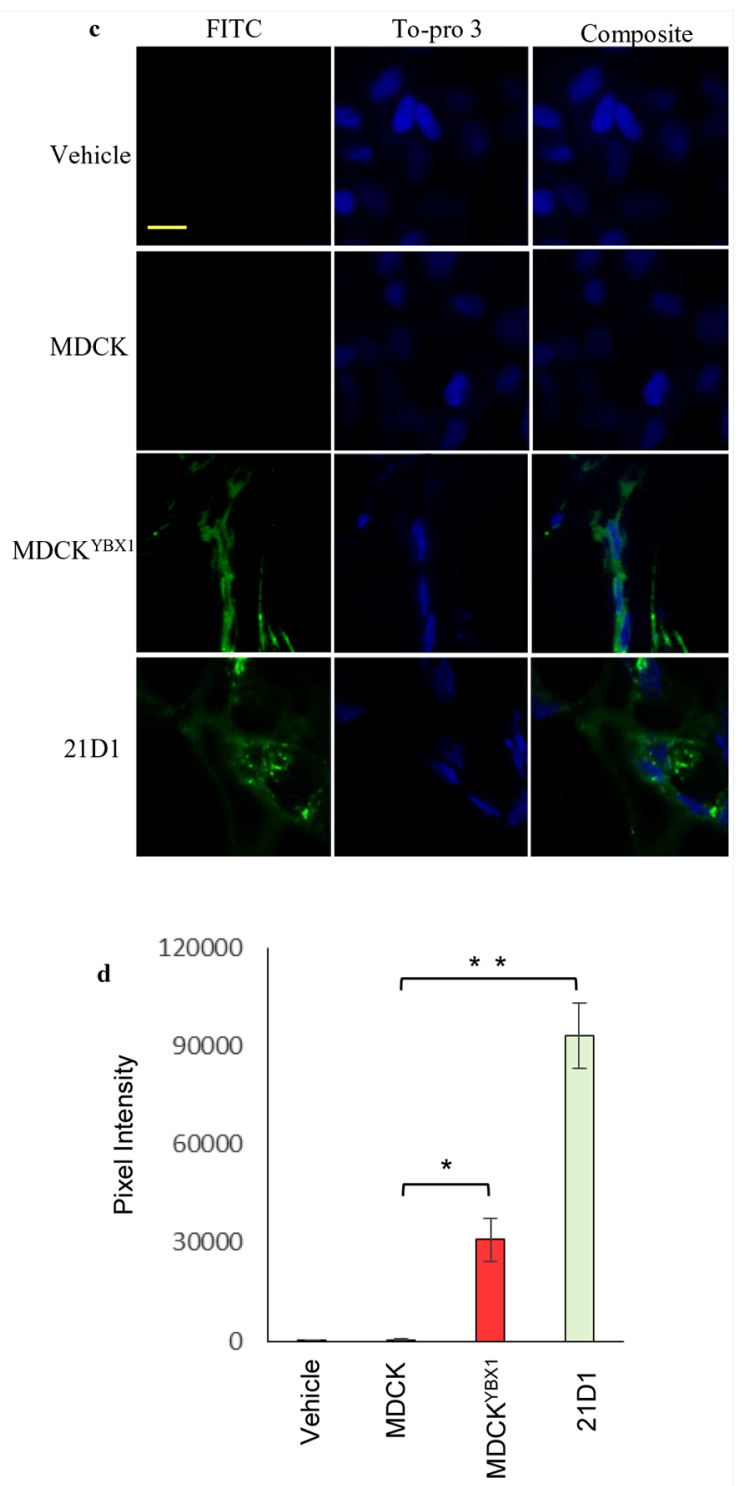

Figure 3: Exosomes from oncogenic cells promote endothelial cell angiogenesis in vitro and in vivo. a. Transwell assay was used to measure $2 \mathrm{~F}-2 \mathrm{~B}$ cell migration following supplementation with exosomes $(30 \mu \mathrm{g})$ from MDCK, MDCK ${ }^{\mathrm{YBX} 1}$ or $21 \mathrm{D} 1 \mathrm{cells}$. After 24 $\mathrm{h}$, migrating cells that passed through the transwell were stained with DAPI (blue), imaged, and counted. Scale bar $=100 \mu \mathrm{m}$. ( $n=3$; average $\left.\pm \mathrm{SEM},{ }^{*} \mathrm{p}<0.05,{ }^{*} \mathrm{p}<0.01\right)$. b. Tube formation assays were conducted using $1 \mathrm{mg} / \mathrm{mL}$ Matrigel. $2 \mathrm{~F}-2 \mathrm{~B}$ cells were seeded on Matrigel and supplemented with exosomes $(30 \mu \mathrm{g})$. After $24 \mathrm{~h}$ of culture, tube formation was analysed and imaged. Scale bar $=50 \mu \mathrm{m}$ (representative images from $n=3)$. c. In vivo analysis of Matrigel plugs containing $2 \mathrm{~F}-2 \mathrm{~B}$ cells $\left(2.5 \times 10^{5}\right)$ supplemented with exosomes $(30 \mu \mathrm{g})$. Plugs were subcutaneously injected into NOD/SCID mice in both inguinal regions. After 21 days, IP tail vein injections of FITC-dextran were performed and animals sacrificed after $1 \mathrm{~h}$. Matrigel plugs were sectioned $(12 \mu \mathrm{m})$, and imaged by confocal microscopy to reveal FITCdextran (green) and To-pro 3 (blue) expression. Scale bar $=10 \mu \mathrm{m}$. d. Quantitative analysis of FITC-dextran expression in exosome treated matrigel plugs. Pixel intensities of FITC-dextran fluorescence (green) were determined using Image J software (V 1.5). ( $n=5$; average \pm $\mathrm{SEM}, * \mathrm{p}<0.05, * * \mathrm{p}<0.01)$. 
differentially expressed (Fold change $>2$ and $\mathrm{p}$-value $<$ 0.05) (Supplementary Table S2). Unbiased gene ontology mining uncovered several cancer-associated/oncogenic proteins with elevated expression in $\mathrm{MDCK}^{\mathrm{YBX} 1}$ exosomes, including signalling proteins (K-Ras, RhoC, Rac1, and H-Ras) (Figure 4a, Supplementary Table S3). Additionally, proteins implicated in angiogenesis including ITGB1BP1, ENPEP, were enriched in $\mathrm{MDCK}^{\mathrm{YBX} 1}$ exosomes (Figure 4b, Supplementary Table S3). Furthermore, examination of cell motility proteins highlighted increased abundance of Rac1 in MDCK ${ }^{\mathrm{YBX} 1}$ exosomes (Figure 4c, Supplementary Table S3). We overlay, quantitative comparisons of exosome proteins from MDCK and 21D1 cells, and observed many similar cancer associated proteins were also up-regulated in 21D1 exosomes (Figure 4a). However, proteins associated with angiogenesis (NRP1, NRP2 and TNFRSF12A) and cell motility (BRK1 and ITGB4) in 21D1 exosomes were very different from those proteins up-regulated in MDCK ${ }^{\mathrm{YBX} 1}$ exosomes (Figure 4b-4c). This suggests that 21D1 cells may utilize a different suite of molecular effectors in exosomes to promote angiogenesis, and these may be downstream of oncogenic H-Ras.

\section{MDCK $^{\mathrm{YBX} 1}$ exosomes are enriched with activated Rac1}

Elevated expression of Rac1 in $\mathrm{MDCK}^{\mathrm{YBX} 1}$ exosomes was selected for further investigation given its known association in promoting cell motility and angiogenesis. Western blotting validated increased Rac1 expression in MDCK $^{\mathrm{YBX} 1}$ exosomes, compared to MDCK exosomes (Figure 5a). In addition, 2F-2B cells were supplemented with either $\mathrm{MDCK}, \mathrm{MDCK}^{\mathrm{YBX} 1}$, or 21D1 exosomes, and blotting of cellular lysates revealed increased Rac1 levels in cells treated with MDCK ${ }^{\mathrm{YBX} 1}$ exosomes (Figure 5b, Supplementary Figure S5). This suggests that these exosomes containing elevated Rac 1 could act as delivery vehicles to transfer cargo to recipient cells. To confirm whether Rac1 in MDCK ${ }^{\mathrm{YBX} 1}$ exosomes represented active Rac1, we next immunoisolated GTP-bound Rac1 from exosomes using PAK-PBD agarose beads. As controls to demonstrate specificity of isolation, MDCK ${ }^{\mathrm{YBX} 1}$ exosomes were lysed, and Rac1 loaded with GDP (negative) or GTP (positive) (Figure 5c, Lanes 1-2). Simultaneously, GTP-Rac1 was isolated from MDCK, MDCK ${ }^{\mathrm{YBX} 1}$ and 21D1 exosome lysates, revealing highest expression in $\mathrm{MDCK}^{\mathrm{YBX} 1}$ exosomes (Figure 5c, Lanes 3-5, and Supplementary Figure S6). Furthermore, comparison of known Rac1 interactions in the STRING database (Supplementary Figure S7) with our proteomics dataset (Supplementary Table S1) revealed that p21-activated kinase 2 (PAK2) was also abundantly expressed in $\mathrm{MDCK}^{\mathrm{YBX} 1}$ exosomes. Therefore, these exosomes contain active Rac1 as well as downstream mediators that can propagate Racl signalling.

\section{Inhibition of Rac1 signalling in recipient endothelial cells inhibits angiogenesis promoted by MDCK $^{\mathrm{YBX} 1}$ exosomes}

To validate the ability of $\mathrm{MDCK}^{\mathrm{YBX} 1}$ exosomes to stimulate angiogenesis in recipient cells via Rac1 signaling, we inhibited downstream Rac1 targets such as PAKs in endothelial cells prior to exosome treatment. NonPAK-inhibited 2F-2B cells show increased tube length formation and branch points following $\mathrm{MDCK}^{\mathrm{YBX} 1}$ and 21D1 exosome supplementation, but MDCK exosomes had no effect compared to the vehicle control (Figure 5d). However, treatment of 2F-2B cells with FRAX597, a Group I PAK inhibitor [25], reduced tube formation in MDCK $^{\mathrm{YBX} 1}$ exosome-treated cells to baseline, but did not impede tube formation in 21D1-exosome-treated cells to the same extent (Figure 5e). We also performed the same experiment with PF-3758309, a compound that targets both Group I and II PAKs [26]. Similar to FRAX597 experiments, we observed the tube length and branch points of $2 \mathrm{~F}-2 \mathrm{~B}$ cells treated with $\mathrm{MDCK}^{\mathrm{YBX} 1}$ exosomes, reduced to baseline and that of cells treated with MDCK exosomes (Figure 5f), while 2F-2B cells treated with 21D1 exosomes were not altered dramatically (Figure 5f). Similar functional experiments were performed in recipient Human Umbilical Vein Endothelial Cells (HUVECs) (Supplementary Figure S8), further confirming the ability of exosomal Rac1 signalling to promote the angiogenic behaviour endothelial cells. Together, these experiments demonstrate that the angiogenic effects conferred by $\mathrm{MDCK}^{\mathrm{YBX} 1}$ exosomes can be blocked by inhibiting downstream PAK signalling in recipient cells.

\section{DISCUSSION}

The TM contains various EVs and soluble protein factors that can enhance the metastatic cascade [27]. In this study, we investigated whether exosomes released from cells undergoing EMT (partial and complete) could promote angiogenesis in recipient endothelial cells. The angiogenic properties observed in $2 \mathrm{~F}-2 \mathrm{~B}$ cells were most pronounced when cells were stimulated with 21D1 exosomes, compared to $\mathrm{MDCK}^{\mathrm{YBX} 1}$ exosomes. This suggests that increased donor cell oncogenicity may translate into their exosomes being more potent, and lead to more heightened functional effects in recipient endothelial cells (Figure 6a). Moreover, we suspect that this property may be attributed to the molecular composition of exosomes from the donor cell (Figure 6b), and being driven by molecular perturbations in the cell (elevated YBX1 vs H-Ras).

We have previously analysed the protein constituents of 21D1 exosomes [22], and in this study focussed on molecular effectors that may promote angiogenesis. Compared to MDCK exosomes, 21D1 exosomes were enriched with angiogenesis-associated proteins NRP1, 


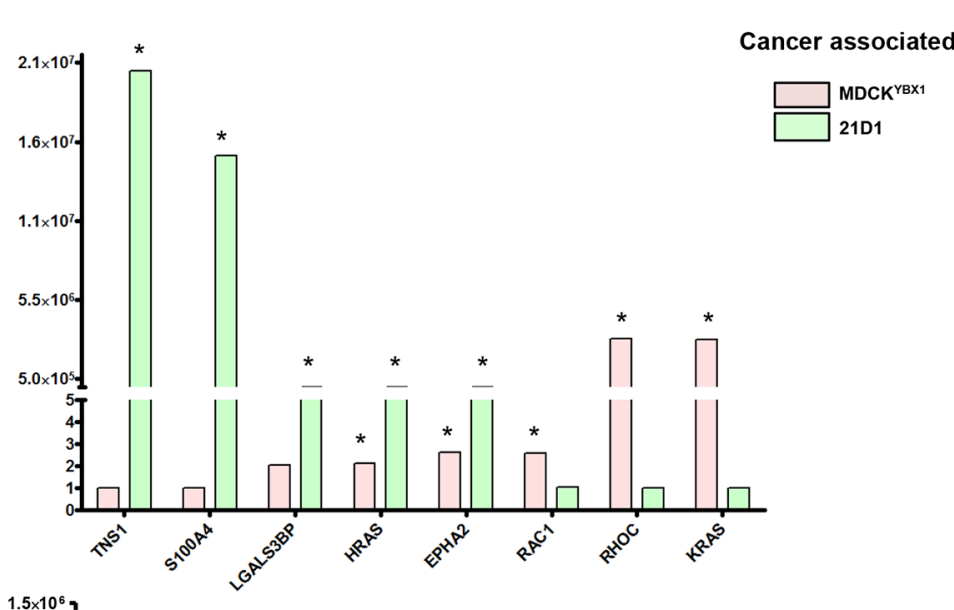

b
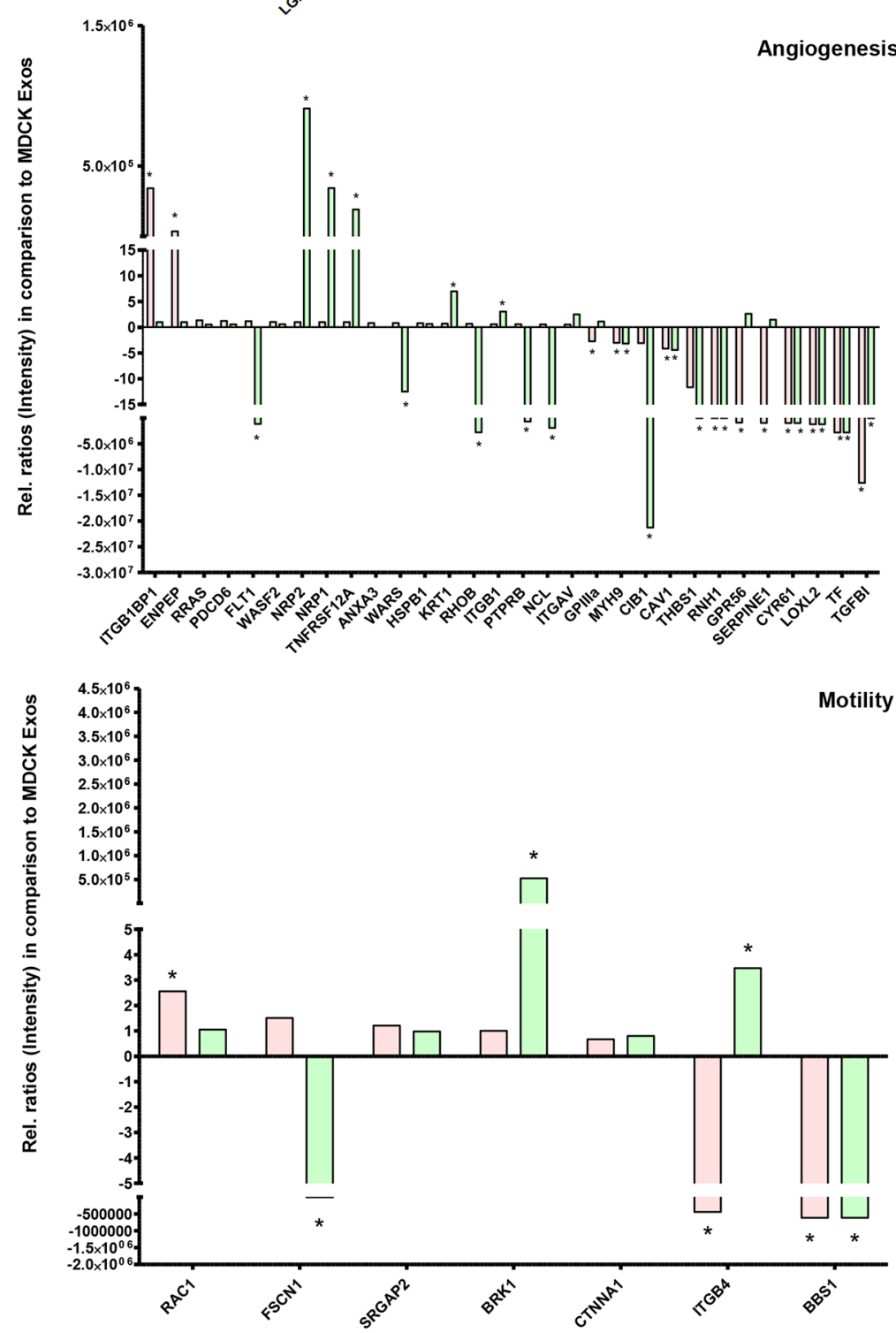

Figure 4: Proteomic-based quantification of factors enriched in MDCK ${ }^{\mathrm{YBX} 1}$ or $21 \mathrm{D1}$ exosomes, compared to MDCK exosomes. Exosomes were isolated from all three EMT cell lines and subjected to mass spectrometry analysis. Label-free quantification using LFQ intensity (MaxQuant) was used to reveal significant enrichment of factors associated with a. cancer progression, b. angiogenesis, and c. cell motility in $\mathrm{MDCK}^{\mathrm{YBX} 1}$ or $21 \mathrm{D} 1$ exosomes, relative to MDCK exosomes $\left(n=2,{ }^{*} \mathrm{p}<0.05\right)$. 

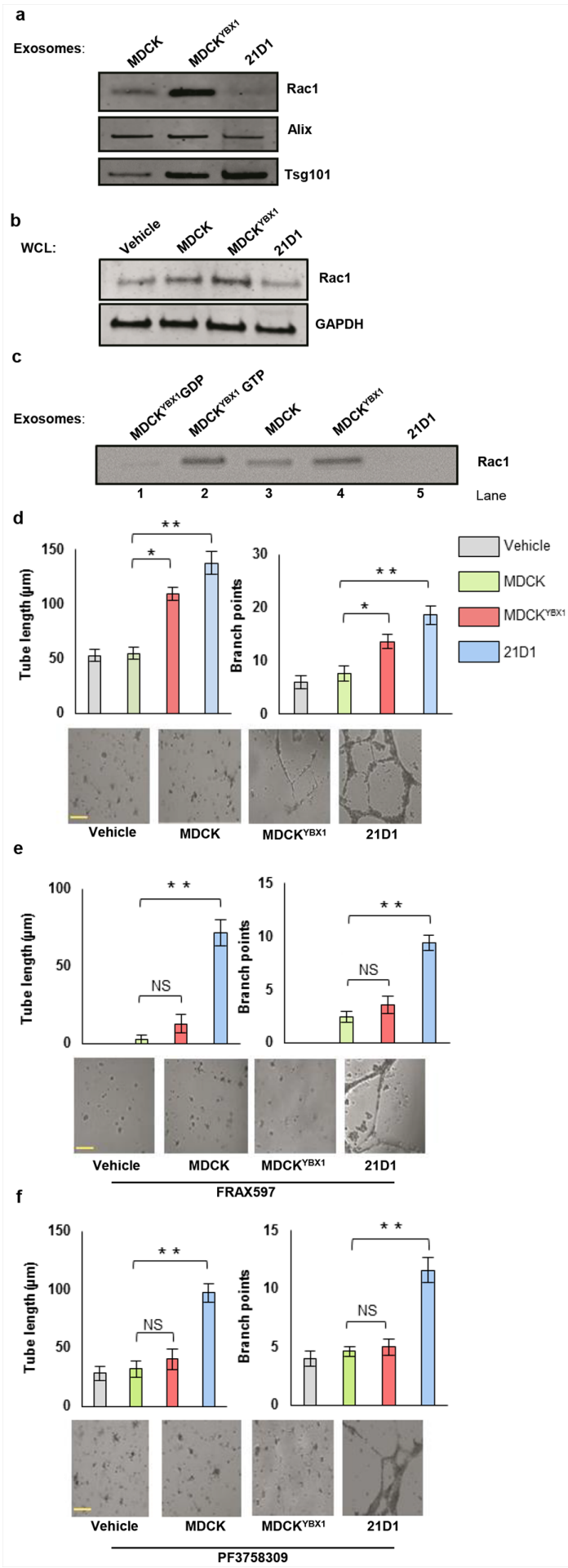

Figure 5: MDCK $^{\mathrm{YBX} 1}$ exosomes contain active Rac1 and promote 2F-2B cell tube formation. a. Expression of Rac1 in exosomes from MDCK, MDCK ${ }^{\mathrm{YBX} 1}$ and $21 \mathrm{D} 1$ cells by western immuno-blotting. b. Western-blot determination of Rac1 expression in 2F-2B cellular lysates following supplementation with exosomes from EMT cell lines. c. Detection of active Rac1 in exosomes using the Rac1 activation assay kit (Cell Biolabs). Controls were loaded with either GDP or GTP (Lanes 1-2), and active Rac1 (GTP-bound) immuno-isolated using PAK-PBD agarose beads. Rac1 was detected by western immuno-blotting. d. Tube formation assays using 2F2B cells supplemented with exosomes were conducted using $1 \mathrm{mg} / \mathrm{mL}$ Matrigel, and tube length and branch points quantified. e-f. Tube formation assays using $2 \mathrm{~F}-2 \mathrm{~B}$ cells $\left(7 \times 10^{4}\right)$ treated with PAK inhibitors, prior to exosome supplementation. Cells were treated with either (e) FRAX597 $(1 \mu \mathrm{M})$ or (f) PF-3758309 $(1 \mu \mathrm{M})$ for $1 \mathrm{~h}$, and seeded onto Matrigel. 2F-2B cells were supplemented with exosomes $(30 \mu \mathrm{g})$. After $24 \mathrm{~h}$ culture, tube formation was analysed and imaged. Scale bar $=50 \mu \mathrm{m}$. (representative images from $n=3,{ }^{*} \mathrm{p}<0.05,{ }^{* *} \mathrm{p}<0.01$ and $\mathrm{NS}=$ no significant difference). 


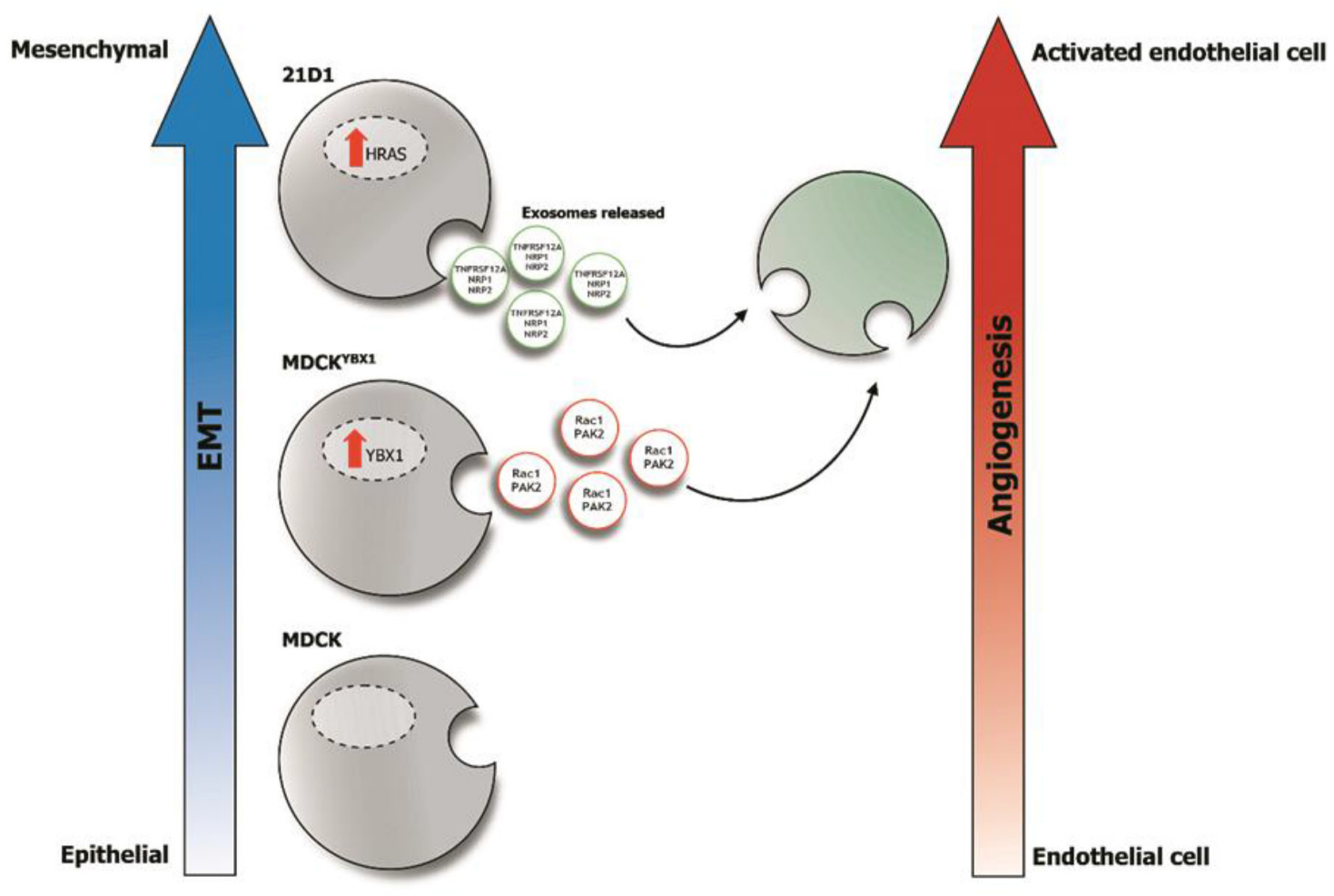

b

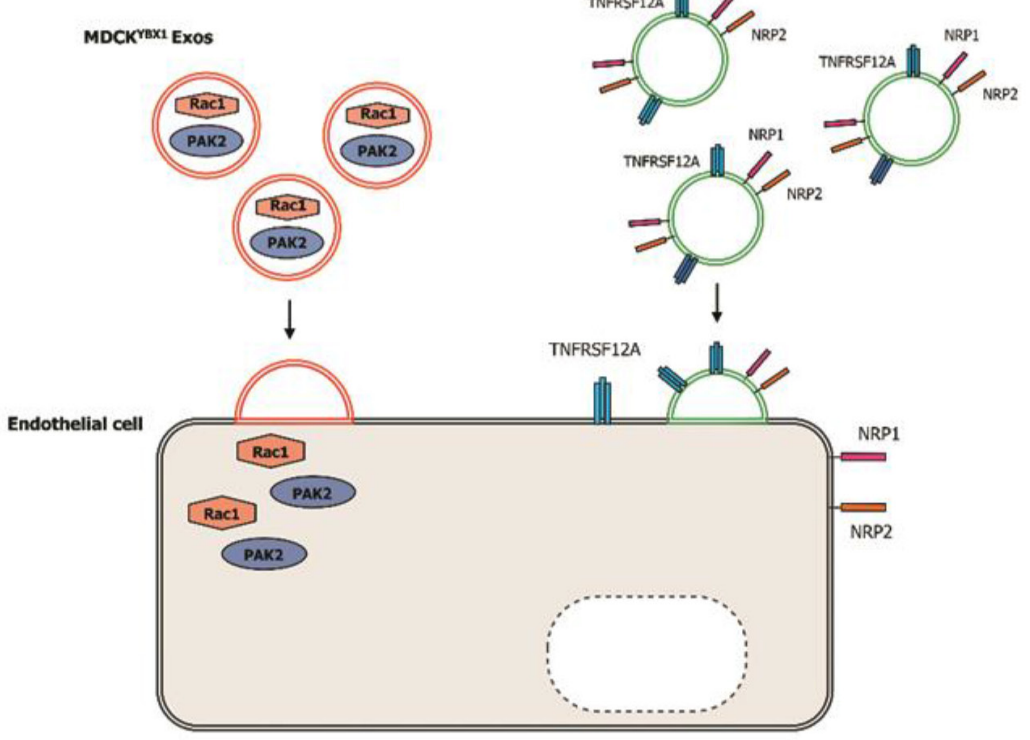

Figure 6: Exosomes released from oncogenic cells undergoing EMT can promote angiogenesis in recipient endothelial cells. a. Elevated expression of YBX1 in MDCK cells induces p-EMT, while H-Ras induces a complete mesenchymal-like phenotype (21D1 cells). Exosomes derived from these cells can activate recipient endothelial cells, and enhance their angiogenic behavior. 21D1 exosomes produce a greater angiogenic response, compared to $\mathrm{MDCK}^{\mathrm{YBX} 1}$ cells, possibly from differential molecular constituents. $\mathbf{b}$. Exosome cargo can be delivered to endothelial cells and influence their angiogenic behavior. Soluble proteins such as Rac1 and PAK2 may directly impact downstream cellular signaling pathways, while transfer of exosome transmembrane proteins (NRP1, NRP2, or TNFRSF12A) could alter endothelial cell surface interactions. 
NRP2, and TNFRSF12A. Notably, all these proteins are transmembrane receptors, however, the functional significance of their identification in 21D1 exosomes is still not clear. NRP1 and NRP2 are 120-130 kDa multifunctional receptors that exist in multiple isoforms and soluble forms $[28,29]$. NRP1 binds and complexes with both VEGFR-1 and VEGFR-2, and potentiates the binding of VEGF-A and activation of pro-angiogenic signalling [30, 31]. Further, NRP2 interacts as a co-receptor with VEGFR-2 and VEGFR-3 and promotes human endothelial cell survival and migration [32]. As VEGF can bind to NRP1, it is tempting to speculate that exosomal NRP1 may help present VEGF to recipient endothelial cells, or stabilise their interaction. Interestingly, we have previously published that VEGF levels were dramatically elevated in the secretome from 21D1 cells, compared to MDCK and $\mathrm{MDCK}^{\mathrm{YBX} 1}$ cells [23]. Therefore, it may be possible that soluble release of VEGF and exosomal NRP1 and NRP2 from 21D1 cells may work synergistically to activate endothelial cell angiogenesis. We anticipate that the PI3K and p38/MAPK pathways may be involved in transducing the signals for endothelial cell migration, survival, and vascular permeability [33].

$\mathrm{MDCK}^{\mathrm{YBX} 1}$ exosome protein constituents were markedly different from that of 21D1, and enriched with the Ras-related small GTPase of the Rho family, Rac1. Cellular Rac1 is involved in angiogenesis [34], and activates endothelial cell lumen and tubule formation [35, 36]. As we validated that $\mathrm{MDCK}^{\mathrm{YBX} 1}$ exosomes contain the highest levels of GTP-bound Rac1, we anticipate that following exosome fusion and transfer of active Rac1 to endothelial cells, downstream Rac1 signalling pathways would be activated. It is also possible that GTP-Rac1 could activate molecular effectors in the exosome prior to fusion with the recipient cell membrane. Strikingly, PAK2, a known Rac1 target, was also uniquely found in $\mathrm{MDCK}^{\mathrm{YBX} 1}$ exosomes. Therefore, $\mathrm{MDCK}^{\mathrm{YBX} 1}$ exosomes may deliver both active Rac1 and PAK2, and this could stimulate angiogenic signalling in recipient cells. The signalling pathways remained to be precisely defined, however, PAK2 is known to signal through PKC [36], and the BMK1/ERK5 pathway has very recently been shown to propagate PAK2 signalling during developmental angiogenesis, as well as mature vessel maintenance [37].

Treatment of 2F-2B and HUVEC cells with PAK inhibitors severely reduced tube length and branch points of these cells. Importantly, increased tube length stimulated by $\mathrm{MDCK}^{\mathrm{YBX} 1}$ exosomes was restored to baseline levels by treatment of recipient cells with PAK inhibitors prior to exosome supplementation, while the effects of 21D1 exosomes were not altered significantly. Thus, increased levels of active Rac1 and PAK2 delivered by $\mathrm{MDCK}^{\mathrm{YBX} 1}$ exosomes would bypass ligand-receptor interactions (VEGF-VEGFR), and enhance the angiogenic phenotype in endothelial cells via an independent downstream pathway.

Our findings imply tumour angiogenesis may be induced from stages early on in the metastatic cascade, such as epithelial cells transitioning into partial or complete mesenchymal-like phenotypes. Exosomes from cells exhibiting $\mathrm{p}$-EMT $\left(\mathrm{MDCK}^{\mathrm{YBX} 1}\right)$ were able to induce angiogenesis in recipient endothelial cells in vitro and in vivo, and the levels of induction increased with exosomes from cells further along the EMT spectrum (21D1 cells). In contrast to classical soluble angiogenic factors that most often act locally within the TM, exosomes may provide a delivery vehicle that is more resistant to degradation, and potentially have a longer range of bioactivity. Exosome fusion may deliver receptor proteins such as NRP1 and TNFRSF12A from exosomes to the surface of endothelial cells, and increase their responsiveness to soluble angiogenic ligands in the TM (Figure 6b). Concurrently, exosome fusion may also deliver soluble cargo such as cellular mediators directly into endothelial cells, and abrogate the requirement for cell surface ligand-receptor interactions (Figure 6b). Therefore, the presence of active Rac1 and PAK2 in exosomes may provide a more direct avenue to induce angiogenesis in recipient endothelial cells, and represent an early mechanism in the metastatic cascade.

\section{MATERIALS AND METHODS}

\section{Cell culture}

MDCK and derivative cell lines $\left(\mathrm{MDCK}^{\mathrm{YBX} 1}\right.$ and 21D1) were generated as described previously [20, 21, 23]. Endothelial cell lines (2F-2B and HUVEC) were obtained from the American Type Culture Collection (Manassas, VA, USA). Cells were cultured in Dulbecco's Modified Eagle's Medium (DMEM) with 10\% fetal bovine serum (FBS), at $37^{\circ} \mathrm{C}$ with $10 \% \mathrm{CO}_{2}$.

\section{Phase contrast microscopy}

Cells were washed with DMEM and imaged on an inverted Nikon Eclipse TE300 microscope equipped with a $10 \times$ objective (Nikon Plan Fluor) using an attached 12.6 mp digital camera (Nikon DXM1200C) [23].

\section{Exosome isolation using OptiPrep ${ }^{\mathrm{TM}}$ density gradient medium}

MDCK, MDCK ${ }^{\mathrm{YBX} 1}$, and 21D1 cells (50x $150 \mathrm{~mm}$ dishes per cell line) were cultured to $70 \%$ confluence in DMEM $+10 \%$ FBS, washed three times with DMEM, and cultured in DMEM for a further $24 \mathrm{~h}$. Conditioned media (CM) was collected $(\sim 750 \mathrm{~mL})$ and centrifuged (480 x $g$ for $5 \mathrm{~min}, 2000 \times \mathrm{g}$ for $10 \mathrm{~min}$ ) as described [24]. Supernatants were centrifuged at $10,000 \times \mathrm{g}$ for 30 $\min$ at $4{ }^{\circ} \mathrm{C}$, and the resulting supernatants at $100,000 \times \mathrm{g}$ for $1 \mathrm{~h}$ to isolate crude exosomes [22, 38, 39]. Exosomes were washed in PBS, and layered onto OptiPrep ${ }^{\mathrm{TM}}$ density gradients for ultracentrifugation at $100,000 \mathrm{xg}$ for $18 \mathrm{~h}$, as previously described [40]. Twelve individual $1 \mathrm{~mL}$ 
fractions were collected (from top of the gradient with increasing density) and each fraction diluted with $2 \mathrm{~mL}$ PBS. After centrifugation at $100,000 \times g$ for $1 \mathrm{~h}$ at $4{ }^{\circ} \mathrm{C}$, supernatants were discarded and pellets washed with $1 \mathrm{~mL}$ PBS and resuspended in $50 \mathrm{ml}$ of PBS for downstream analysis [38].

\section{Cryo-transmission electron microscopy (cryo-EM)}

Cryo-EM imaging of purified exosome preparations was performed as previously described $[22,39]$.

\section{Scanning electron microscopy (s-EM)}

s-EM analyses were performed essentially as described previously [41], with minor modifications. Briefly, exosomal preparations $(\sim 3 \mu \mathrm{g})$ were analyzed on a scanning electron microscope (JEOL JSM 6340F) equipped with a cold field electron emission source. Images were acquired with $10 \mathrm{kV}$ acceleration voltage, 6 mm working distance (WD), 10 fields of view, and an inlens secondary electron detector (SEI).

\section{Dynamic light scattering (DLS)}

DLS analyses were performed as previously described [39].

\section{Protein quantification and immunoblotting}

Protein content was estimated by 1D-SDS-PAGE/ SYPRO Ruby protein staining-based densitometry, as previously described [22]. For immunoblotting (10 $\mu \mathrm{g})$, membranes were probed with primary antibodies [mouse anti-Rac1 (Abcam, 1:1000), mouse anti-Alix mouse (Cell Signalling, 1:1000), mouse anti-TSG101 (Cell Signalling, 1:1000), and mouse anti-GAPDH (Ambion, 1:12,000)] for $1 \mathrm{~h}$ in TTBS (50 mM Tris, $150 \mathrm{mM} \mathrm{NaCl}, 0.05 \%$ (v/v) Tween 20) followed by incubation with corresponding secondary antibodies; IRDye 800 goat anti-mouse IgG or IRDye 700 goat anti-rabbit IgG (1:15000, LI-COR Biosciences), for $1 \mathrm{~h}$ at RT in TTBS. Immunoblots were imaged using the Odyssey Infrared Imaging System, (v3.0, LI-COR Biosciences, Nebraska USA).

\section{Exosome labelling and internalisation}

Exosomes $(300 \mu \mathrm{g})$ were labelled with $1 \mu \mathrm{M}$ DiI lipophilic dye (Invitrogen) and incubated at $37^{\circ} \mathrm{C}$ for 30 min. Excess dye was removed by washing with PBS, and labelled exosomes were re-isolated by OptiPrep ${ }^{\mathrm{TM}}$ density gradient ultracentrifugation (described above). Recipient 2F-2B cells $\left(2 \times 10^{5}\right)$ were incubated with DiI labelled Exos $(10 \mu \mathrm{g})$ for $2 \mathrm{~h}$, fixed in $4 \%(\mathrm{v} / \mathrm{v})$ formaldehyde in PBS for $10 \mathrm{~min}$ at RT, semi-permeabilised $(0.2 \%$ (v/v) Triton X-100 in PBS), washed with wash buffer
$(0.1 \%(\mathrm{w} / \mathrm{v})$ BSA and $0.1 \%(\mathrm{v} / \mathrm{v})$ Tween-20 in PBS), and incubated with DAPI (1:5,000, Invitrogen) and/or primary antibody mouse anti-Actin (1:500, Sigma). Cells were incubated with Alexa Fluor 488-conjugated goat antimouse IgG (Invitrogen) at RT, and subjected to confocal microscopy using a Zeiss LSM 780 confocal microscope with $100 \times$ magnification $(n=3)$.

\section{Endothelial cell migration assay}

For the endothelial migration assay, 2F-2B cells $(2 \times$ $10^{5}$ ) were treated with vehicle control (DMEM 0\% FBS), MDCK, MDCK ${ }^{\mathrm{YBX} 1}$ or $21 \mathrm{D} 1$ exosomes $(30 \mu \mathrm{g})$ for $2 \mathrm{~h}$ at $37^{\circ} \mathrm{C}$. Cells were pelleted at $500 \mathrm{xg}$, resuspended in 100 $\mu \mathrm{L}$ of DMEM and seeded onto Transwell polycarbonate membrane cell culture inserts $(8.0 \mu \mathrm{m}$ pore size, Corning). The inserts were placed into 24-well companion plates with the bottom chamber containing DMEM (0\% FBS). 2F-2B cells were left to migrate through the transwell for $24 \mathrm{~h} 37^{\circ} \mathrm{C}$. Inserts were removed, cells fixed $(4 \%$ (v/v) formaldehyde, $10 \mathrm{~min}$ ), and nuclei stained with DAPI. Non-migrating cells were removed from the upper side of the inserts using cotton swabs. Migrating cells were imaged using an inverted Nikon Eclipse TE300 microscope equipped with an attached $12.6 \mathrm{mp}$ digital camera (Nikon DXM1200C) $(n=3$; average \pm SEM, $* * P$ $<0.01)$.

\section{Endothelial cell tube formation assay}

Endothelial cell tube formation assays were performed as previously described [42]. Briefly, 2F-2B and HUVEC $\left(7 \times 10^{4}\right.$ cells/well $)$ were re-suspended in $\mathrm{DMEM}+5 \% \mathrm{FBS}$, and seeded onto growth factor-reduced BD matrigel $(1 \mathrm{mg} / \mathrm{ml})$ (96-well) for $1 \mathrm{~h}$. Cells were then supplemented for $2 \mathrm{~h}$ with $\mathrm{MDCK}, \mathrm{MDCK}^{\mathrm{YBX} 1}$ or 21D1 Exos $(30 \mu \mathrm{g})$, or the vehicle control (DMEM). For inhibitor based tube formation assays, 2F-2B and HUVEC cells $\left(7 \times 10^{4}\right.$ cells/well $)$ were pre-treated with Rac1 inhibitors: $1 \mu \mathrm{M}$ FRAX597 (Selleck Chem) and $1 \mu \mathrm{M}$ PF3758309 (Selleck Chem) for $1 \mathrm{~h}$. Cells were isolated (480 $\mathrm{x} g .5 \mathrm{~min}$ ) and re-suspended in DMEM $+5 \% \mathrm{FBS}$, and seeded onto growth factor-reduced BD matrigel $(1 \mathrm{mg} /$ $\mathrm{ml})$ (96-well) for $1 \mathrm{~h}$. Cells were then supplemented with MDCK, MDCK ${ }^{\mathrm{YBX} 1}$ or 21D1 Exos $(30 \mu \mathrm{g})$, or the vehicle control (DMEM). Tube-like structures were imaged using Nikon Eclipse TE300 microscope.

\section{Matrigel plug angiogenesis assay}

All experiments were performed in accordance with the guidelines of La Trobe University Ethics committee. In vivo matrigel plug angiogenesis assays were performed as previously described [43]. 2F-2B cells $\left(2.5 \times 10^{5}\right.$ cells $)$ were treated with $30 \mu \mathrm{g}$ of MDCK, MDCK ${ }^{\mathrm{YBX} 1}, 21 \mathrm{D} 1$ exosomes, or vehicle control (DMEM), pre-mixed with growth factor reduced matrigel (1 mg/ml, BD Biosciences) 
and DMEM (0\% FBS, 0.5\% BSA (w/v) and 1\% (v/v) Pen strep (Life Technologies), and injected subcutaneously into NOD/SCID male mice $(n=8)$ in both inguinal regions. After 21 days, IP tail vein injections of FITC-dextran $150 \mathrm{kDa}$ (Invitrogen) were administered, and animals sacrificed after $1 \mathrm{~h}$. Matrigel plugs were excised, fixed in $4 \%$ paraformaldehyde, cryo-protected for $10 \mathrm{~h}$ in $20 \%$ $(\mathrm{w} / \mathrm{v})$ sucrose and frozen in Tissue-Tek OCT compound (Sakura Finetechnical). Fresh sections (12 $\mu \mathrm{m})$ were prepared using a cryostat microtome (Leica CM1950), nuclei stained with To-pro-3 (1:1000), and imaged using a Zeiss LSM 780 confocal microscope.

\section{Proteomic analysis}

Proteomic experiments were performed in duplicate as previously described [23]. Briefly, exosomes from each cell line $(10 \mu \mathrm{g})$ were lysed in SDS sample buffer $(4 \%$ (w/v) SDS, 20\% (v/v) glycerol, 0.01\% (v/v) bromophenol blue, $0.125 \mathrm{M}$ Tris-HCl, pH 6.8), and proteins separated by SDS-PAGE, and visualized by Imperial ${ }^{\text {TM }}$ Protein Stain (Invitrogen). Individual samples were excised, destained (50 $\mathrm{mM}$ ammonium bicarbonate/acetonitrile), reduced (10 mM DTT (Calbiochem) for $30 \mathrm{~min}$ ), alkylated (50 $\mathrm{mM}$ iodoacetic acid (Fluka) for $30 \mathrm{~min}$ ) and trypsinized $(0.2 \mu \mathrm{g}$ trypsin (Promega Sequencing Grade) for $16 \mathrm{~h}$ at $37^{\circ} \mathrm{C}$ ). A nanoflow UPLC instrument (Ultimate 3000 RSLCnano, Thermo Fisher Scientific) was coupled online to an Orbitrap Elite mass spectrometer (Thermo Fisher Scientific) with a nanoelectrospray ion source (Thermo Fisher Scientific). Peptides were loaded (Acclaim PepMap100 C18 5 mm 100Å, Thermo Fisher Scientific) and separated (PepMapRSLC C18, $50 \mathrm{~cm}, 75 \mu \mathrm{m}$ inner

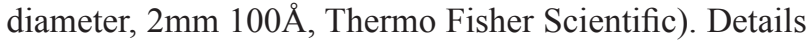
of the operation of the mass spectrometer are described previously [23].

\section{Database searching and protein identification}

Raw data was processed using MaxQuant [44] (v1.1.1.25) and searched with Andromeda against the Uniprot Canine database comprising 28698 entries (Jul2015) and common contaminants $[45,46]$. Data was searched as described [23] with a parent tolerance of 10 ppm, fragment tolerance of $0.5 \mathrm{Da}$ and minimum peptide length 7, with FDR 1\% at the peptide and protein levels, and data examined with label-free quantitation (LFQ) [47]. LFQ intensity values were normalized for protein length and fold change ratios calculated. Contaminants and reverse database identifications were excluded from data analysis.

\section{Rac1 activation assay}

Activation of Rac1 was performed according to manufacturer's instructions using Rac1 activation assay kit (Cell Biolabs) [48]. Briefly, MDCK ${ }^{\mathrm{YBX} 1}$ Exos $(75 \mu \mathrm{g})$ were pre-treated for $30 \mathrm{~min}$ at $30^{\circ} \mathrm{C}$ with agitation, with $10 \mathrm{mM}$ GTP $\gamma \mathrm{S}$ or GDP in assay buffer (125 mM HEPES, $\mathrm{pH} 7.5,750 \mathrm{mM} \mathrm{NaCl}, 5 \% \mathrm{NP}-40,50 \mathrm{mM} \mathrm{MgCl}, 5 \mathrm{mM}$ EDTA, 10\% glycerol) to generate positive and negative controls. These controls and MDCK, MDCK ${ }^{\mathrm{YBX} 1}, 21 \mathrm{D} 1$ exosome samples $(75 \mu \mathrm{g})$ were incubated with $20 \mu \mathrm{g}$ PAK-PBD agarose beads (Cell Biolabs) and incubated for $1 \mathrm{~h}$ at $4^{\circ} \mathrm{C}$ with gentle agitation. PAK-PBD agarose beads were pelleted by benchtop centrifugation, washed in assay buffer, resuspended in SDS sample buffer, and subjected to immunoblotting or stored at $4{ }^{\circ} \mathrm{C}$ for further use.

\section{Statistical analysis}

Student's $t$-tests were calculated using GraphPad (v5.0), with $* p<0.05$ and $* * p<0.01$ considered statistically significant.

\section{ACKNOWLEDGMENTS}

We thank Maoshan Chen for performing statistical analysis, Dr. Jacqueline Orian for assistance with immunohistochemistry, and Erica J. Brodie for artistic support. Authors are supported, in part, by the National Health and Medical Research Council of Australia program grants APP487922 (RJS), project grant APP433619 (H-JZ), and Early Career CJ Martin Fellowship APP1037043 (RAM). H-JZ is also supported by the Melbourne Research Grant Support Scheme (The University of Melbourne). SKG is supported by a La Trobe University Postgraduate Scholarship. We acknowledge the La Trobe University-Comprehensive Proteomics Platform for providing infrastructure and expertise for Capability A: Protein Identification \& Quantitation.

\section{CONFLICTS OF INTEREST}

The authors declare no conflict of interest.

\section{Abbreviations}

21D1, Ras-transformed MDCK cells; CM, Conditioned media; CSF-1, Colony stimulating factor 1; DMEM, Dulbecco's Modified Eagle's Medium; ECM, Extracellular matrix; EMT, Epithelial-mesenchymal transitionFBS, Fetal bovine serum; MDCK, MadinDarby canine kidney; MMP1, Matrix metalloproteinase 1; NMWL, Nominal molecular weight limit; NRP1, Neuropilin-1; NRP2, Neuropilin-2; PAK2, p21-activated kinase 2; P-EMT, partial epithelial mesenchymal transition; TGF- $\beta$, Transforming growth factor beta; TM, Tumour microenvironment; TNFRS12A, Tumor necrosis factor receptor superfamily member 12A; VEGF, Vascular endothelial growth factor; YBX1, Y-box binding protein 1 . 


\section{REFERENCES}

1. Albini A, Sporn MB. The tumour microenvironment as a target for chemoprevention. Nature reviews Cancer. 2007; 7:139-147.

2. Berx G, Raspe E, Christofori G, Thiery JP, Sleeman JP. Pre-EMTing metastasis? Recapitulation of morphogenetic processes in cancer. Clinical \& experimental metastasis. 2007; 24:587-597.

3. Jing Y, Han Z, Zhang S, Liu Y, Wei L. EpithelialMesenchymal Transition in tumor microenvironment. Cell \& bioscience. 2011; 1:29.

4. Ungefroren H, Sebens S, Seidl D, Lehnert H, Hass R. Interaction of tumor cells with the microenvironment. Cell communication and signaling : CCS. 2011; 9:18.

5. Lamouille S, Xu J, Derynck R. Molecular mechanisms of epithelial-mesenchymal transition. Nature reviews Molecular cell biology. 2014; 15:178-196.

6. Yang J, Weinberg RA. Epithelial-mesenchymal transition: at the crossroads of development and tumor metastasis. Developmental cell. 2008; 14:818-829.

7. Thiery JP. Epithelial-mesenchymal transitions in tumour progression. Nature reviews Cancer. 2002; 2:442-454.

8. Weis SM, Cheresh DA. Tumor angiogenesis: molecular pathways and therapeutic targets. Nature medicine. 2011; 17:1359-1370.

9. Hendrix MJ, Seftor EA, Hess AR, Seftor RE. Vasculogenic mimicry and tumour-cell plasticity: lessons from melanoma. Nature reviews Cancer. 2003; 3:411-421.

10. Psaila B, Lyden D. The metastatic niche: adapting the foreign soil. Nature reviews Cancer. 2009; 9:285-293.

11. Carmeliet $P$, Jain RK. Molecular mechanisms and clinical applications of angiogenesis. Nature. 2011; 473:298-307.

12. Greening DW, Gopal SK, Mathias RA, Liu L, Sheng J, Zhu HJ, Simpson RJ. Emerging roles of exosomes during epithelial-mesenchymal transition and cancer progression. Seminars in cell \& developmental biology. 2015; 40:60-71

13. Kahlert C, Kalluri R. Exosomes in tumor microenvironment influence cancer progression and metastasis. Journal of molecular medicine. 2013; 91:431-437.

14. Mineo M, Garfield SH, Taverna S, Flugy A, De Leo G, Alessandro R, Kohn EC. Exosomes released by K562 chronic myeloid leukemia cells promote angiogenesis in a Src-dependent fashion. Angiogenesis. 2012; 15:33-45.

15. Sheldon H, Heikamp E, Turley H, Dragovic R, Thomas P, Oon CE, Leek R, Edelmann M, Kessler B, Sainson RC, Sargent I, Li JL, Harris AL. New mechanism for Notch signaling to endothelium at a distance by Deltalike 4 incorporation into exosomes. Blood. 2010; 116:2385-2394.

16. Umezu T, Ohyashiki K, Kuroda M, Ohyashiki JH. Leukemia cell to endothelial cell communication via exosomal miRNAs. Oncogene. 2013; 32:2747-2755.
17. Zhang B, Wu X, Zhang X, Sun Y, Yan Y, Shi H, Zhu Y, Wu L, Pan Z, Zhu W, Qian H, Xu W. Human umbilical cord mesenchymal stem cell exosomes enhance angiogenesis through the Wnt4/beta-catenin pathway. Stem cells translational medicine. 2015; 4:513-522.

18. Sharghi-Namini S, Tan E, Ong LL, Ge R, Asada HH. Dl14containing exosomes induce capillary sprout retraction in a 3D microenvironment. Scientific reports. 2014; 4:4031.

19. Chen YS, Mathias RA, Mathivanan S, Kapp EA, Moritz RL, Zhu HJ, Simpson RJ. Proteomics profiling of MadinDarby canine kidney plasma membranes reveals Wnt-5a involvement during oncogenic H-Ras/TGF-beta-mediated epithelial-mesenchymal transition. Molecular \& cellular proteomics. 2011; 10:M110 001131.

20. Mathias RA, Chen YS, Wang B, Ji H, Kapp EA, Moritz RL, Zhu HJ, Simpson RJ. Extracellular remodelling during oncogenic Ras-induced epithelial-mesenchymal transition facilitates MDCK cell migration. Journal of proteome research. 2010; 9:1007-1019.

21. Mathias RA, Wang B, Ji H, Kapp EA, Moritz RL, Zhu HJ, Simpson RJ. Secretome-based proteomic profiling of Rastransformed MDCK cells reveals extracellular modulators of epithelial-mesenchymal transition. Journal of proteome research. 2009; 8:2827-2837.

22. Tauro BJ, Mathias RA, Greening DW, Gopal SK, Ji H, Kapp EA, Coleman BM, Hill AF, Kusebauch U, Hallows JL, Shteynberg D, Moritz RL, Zhu HJ, et al. Oncogenic H-ras reprograms Madin-Darby canine kidney (MDCK) cell-derived exosomal proteins following epithelialmesenchymal transition. Molecular \& cellular proteomics. 2013; 12:2148-2159.

23. Gopal SK, Greening DW, Mathias RA, Ji H, Rai A, Chen M, Zhu HJ, Simpson RJ. YBX1/YB-1 induces partial EMT and tumourigenicity through secretion of angiogenic factors into the extracellular microenvironment. Oncotarget. 2015; 6:13718-13730. doi: 10.18632/oncotarget.3764.

24. Ji H, Greening DW, Barnes TW, Lim JW, Tauro BJ, Rai A, Xu R, Adda C, Mathivanan S, Zhao W, Xue Y, Xu T, Zhu HJ, et al. Proteome profiling of exosomes derived from human primary and metastatic colorectal cancer cells reveal differential expression of key metastatic factors and signal transduction components. Proteomics. 2013; 13:1672-1686.

25. Licciulli S, Maksimoska J, Zhou C, Troutman S, Kota S, Liu Q, Duron S, Campbell D, Chernoff J, Field J, Marmorstein R, Kissil JL. FRAX597, a small molecule inhibitor of the p21-activated kinases, inhibits tumorigenesis of neurofibromatosis type 2 (NF2)-associated Schwannomas. The Journal of biological chemistry. 2013; 288:29105-29114.

26. Murray BW, Guo C, Piraino J, Westwick JK, Zhang C, Lamerdin J, Dagostino E, Knighton D, Loi CM, Zager M, Kraynov E, Popoff I, Christensen JG, et al. Smallmolecule p21-activated kinase inhibitor PF-3758309 is a potent inhibitor of oncogenic signaling and tumor growth. 
Proceedings of the National Academy of Sciences of the United States of America. 2010; 107:9446-9451.

27. Peinado H, Lavotshkin S, Lyden D. The secreted factors responsible for pre-metastatic niche formation: old sayings and new thoughts. Seminars in cancer biology. 2011; 21:139-146.

28. Soker S, Takashima S, Miao HQ, Neufeld G, Klagsbrun M. Neuropilin-1 is expressed by endothelial and tumor cells as an isoform-specific receptor for vascular endothelial growth factor. Cell. 1998; 92:735-745.

29. Maden CH, Gomes J, Schwarz Q, Davidson K, Tinker A, Ruhrberg C. NRP1 and NRP2 cooperate to regulate gangliogenesis, axon guidance and target innervation in the sympathetic nervous system. Developmental biology. 2012; 369:277-285.

30. Rollin S, Lemieux C, Maliba R, Favier J, Villeneuve LR, Allen BG, Soker S, Bazan NG, Merhi Y, Sirois MG. VEGF-mediated endothelial P-selectin translocation: role of VEGF receptors and endogenous PAF synthesis. Blood. 2004; 103:3789-3797.

31. Bernatchez PN, Rollin S, Soker S, Sirois MG. Relative effects of VEGF-A and VEGF-C on endothelial cell proliferation, migration and PAF synthesis: Role of neuropilin-1. Journal of cellular biochemistry. 2002; 85:629-639.

32. Favier B, Alam A, Barron P, Bonnin J, Laboudie P, Fons P, Mandron M, Herault JP, Neufeld G, Savi P, Herbert JM, Bono F. Neuropilin-2 interacts with VEGFR-2 and VEGFR-3 and promotes human endothelial cell survival and migration. Blood. 2006; 108:1243-1250.

33. Olsson AK, Dimberg A, Kreuger J, Claesson-Welsh L. VEGF receptor signalling - in control of vascular function. Nature reviews Molecular cell biology. 2006; 7:359-371.

34. Fryer BH, Field J. Rho, Rac, Pak and angiogenesis: old roles and newly identified responsibilities in endothelial cells. Cancer letters. 2005; 229:13-23.

35. Bayless KJ, Davis GE. The Cdc42 and Rac1 GTPases are required for capillary lumen formation in three-dimensional extracellular matrices. Journal of cell science. 2002; 115:1123-1136.

36. Koh W, Mahan RD, Davis GE. Cdc42- and Rac1-mediated endothelial lumen formation requires Pak2, Pak4 and Par3, and PKC-dependent signaling. Journal of cell science. 2008; 121:989-1001.

37. Radu M, Lyle K, Hoeflich KP, Villamar-Cruz O, Koeppen H, Chernoff J. p21-Activated Kinase 2 Regulates Endothelial Development and Function through the Bmk1/Erk5 Pathway. Molecular and cellular biology. 2015; 35:3990-4005.

38. Greening DW, Xu R, Ji H, Tauro BJ, Simpson RJ. A protocol for exosome isolation and characterization: evaluation of ultracentrifugation, density-gradient separation, and immunoaffinity capture methods. Methods in molecular biology. 2015; 1295:179-209.

39. Xu R, Greening DW, Rai A, Ji H, Simpson RJ. Highlypurified exosomes and shed microvesicles isolated from the human colon cancer cell line LIM1863 by sequential centrifugal ultrafiltration are biochemically and functionally distinct. Methods. 2015; 87:11-25.

40. Tauro BJ, Greening DW, Mathias RA, Ji H, Mathivanan S, Scott AM, Simpson RJ. Comparison of ultracentrifugation, density gradient separation, and immunoaffinity capture methods for isolating human colon cancer cell line LIM1863-derived exosomes. Methods. 2012; 56:293-304.

41. Sokolova V, Ludwig AK, Hornung S, Rotan O, Horn PA, Epple M, Giebel B. Characterisation of exosomes derived from human cells by nanoparticle tracking analysis and scanning electron microscopy. Colloids and surfaces B, Biointerfaces. 2011; 87:146-150.

42. Williams TF, Mirando AC, Wilkinson B, Francklyn CS, Lounsbury KM. Secreted Threonyl-tRNA synthetase stimulates endothelial cell migration and angiogenesis. Scientific reports. 2013; 3:1317.

43. Kaafarani I, Fernandez-Sauze S, Berenguer C, Chinot O, Delfino C, Dussert C, Metellus P, Boudouresque F, Mabrouk K, Grisoli F, Figarella-Branger D, Martin PM, Ouafik L. Targeting adrenomedullin receptors with systemic delivery of neutralizing antibodies inhibits tumor angiogenesis and suppresses growth of human tumor xenografts in mice. FASEB journal. 2009; 23:3424-3435.

44. Cox J, Mann M. MaxQuant enables high peptide identification rates, individualized p.p.b.-range mass accuracies and proteome-wide protein quantification. Nature biotechnology. 2008; 26:1367-1372.

45. Cox J, Matic I, Hilger M, Nagaraj N, Selbach M, Olsen JV, Mann M. A practical guide to the MaxQuant computational platform for SILAC-based quantitative proteomics. Nature protocols. 2009; 4:698-705.

46. Cox J, Neuhauser N, Michalski A, Scheltema RA, Olsen JV, Mann M. Andromeda: a peptide search engine integrated into the MaxQuant environment. Journal of proteome research. 2011; 10:1794-1805.

47. Luber CA, Cox J, Lauterbach H, Fancke B, Selbach M, Tschopp J, Akira S, Wiegand M, Hochrein H, O'Keeffe M, Mann M. Quantitative proteomics reveals subset-specific viral recognition in dendritic cells. Immunity. 2010; 32:279-289.

48. Takano A, Ishikawa N, Nishino R, Masuda K, Yasui W, Inai $\mathrm{K}$, Nishimura $\mathrm{H}$, Ito $\mathrm{H}$, Nakayama $\mathrm{H}$, Miyagi $\mathrm{Y}$, Tsuchiya E, Kohno N, Nakamura Y, et al. Identification of nectin-4 oncoprotein as a diagnostic and therapeutic target for lung cancer. Cancer research. 2009; 69:6694-6703. 